\title{
Inversion of gravity data with isostatic constraints
}

\author{
Ahmed Salem ${ }^{1}$, Chris Green ${ }^{2}$, Matthew Stewart ${ }^{3}$, and Davide De Lerma ${ }^{3}$
}

\begin{abstract}
We have developed a simple iterative gravity-inversion approach to map the basement and Moho surfaces of a rift basin simultaneously. Gravity anomalies in rift basins commonly consist of interfering broad, positive crustal-thinning anomalies and narrow, negative sedimentary-basin anomalies. In our model, we assumed that the Moho and basement surfaces are in Airy isostatic equilibrium. An initial planelayered model was iterated to fit the gravity data. We applied the process to a model in which the inverted basement and Moho surfaces matched the model surfaces well and to a gravity profile across the Kosti Basin in Sudan.
\end{abstract}

\section{INTRODUCTION}

Gravity anomalies from density variations within the crust are often complicated in their shape and reduced in their amplitude by the effect of isostacy. A particular example is the case of continental rift basins in which the thinning of the crust under the rift causes a positive gravity anomaly, which tends to counteract the negative gravity anomaly of the sedimentary basin. Similar effects occur over and at the edges of ocean basins. Lateral strength in the crust gives rise to flexural isostacy, in which isostatic compensation extends over a considerable distance from the near-surface mass imbalance. However, in many stretched crust locations, it is found that compensation is relatively local and Airy isostacy is a reasonable model, e.g., studies of the West African margin by Watts and Stewart (1998).

Even for an Airy isostatic model, the two gravity anomalies do not completely cancel as the deeper density contrast of the crustal thinning gives rise to a positive gravity anomaly, which is broader than the negative gravity anomaly produced by the shallow sedi- mentary basin. This enables the gravity anomaly to be modeled, especially if control data are available. Fairhead and Green (1989) use a simple geometric model to represent the crustal thinning and model the residual gravity as being due to sedimentary rift basins. Jorgensen and Bosworth (1989) separate the gravity field using a best-fit, low-order polynomial to address a similar interpretation. Salem et al. (2013) separate gravity data across the Red Sea into sediment and Moho effects based upon wavelength filtering. In each of these cases, the residual gravity can be inverted for basement depth using a method that inverts for the depth of a single interface, e.g., Cordell and Henderson (1968) in the space domain or Oldenburg (1974) using fast Fourier transforms.

In this paper, we present an alternative inversion method for gravity data over simple rift models incorporating constant-density contrasts at the basement and at the Moho. We set a simple Airy-type isostatic relationship as a constraint on our model, such that the shape of the Moho and the base of the sediments are related through the Archimedes principle. The method iterates from a plane-layer starting model to a model that fits the data. We test our method on theoretical gravity data over a basin model and field gravity data across a small rift basin.

\section{METHOD}

The basic isostatic model, sometimes known as the "hiddenlayer" Airy model (e.g., Karner and Watts, 1982), which links the depth to basement $h_{s}$ and depth to Moho $h_{m}$, is illustrated in Figure 1 as

$$
h_{m}=h_{c}+h_{s} \frac{\Delta \rho_{s}}{\Delta \rho_{m}}
$$

where $\Delta \rho_{s}$ is the (negative) density contrast of the sediments relative to the basement, $\Delta \rho_{m}$ is the (positive) density contrast at the Moho (upper mantle relative to lower crust), and $h_{c}$ is the Moho

\footnotetext{
Manuscript received by the Editor 13 May 2014; revised manuscript received 16 July 2014; published online 1 October 2014.

${ }^{1}$ Formerly Nuclear Materials Authority, Cairo, Egypt; presently GETECH, Kitson House, Elmete Hall, Elmete Lane, Leeds, LS8 2LJ, UK. E-mail: ahmedsalem30@yahoo.com; ahmed.salem@getech.com.

${ }^{2}$ Formerly University of Leeds, Leeds, UK; presently GETECH, Kitson House, Elmete Hall, Elmete Lane, Leeds, LS8 2LJ, UK. E-mail: chris.green@ getech .com.

GETECH, Leeds, UK. E-mail: Matthew.stewart@getech.com; davide.delerma@getech.com.

(C) 2014 Society of Exploration Geophysicists. All rights reserved.
} 
depth for basement depth of zero; all depths are positive downward. The Bouguer gravity anomaly over the basic Airy model can be written as

$$
g_{\mathrm{obs}}=g_{m}+g_{s}+g_{c}
$$

where $g_{m}$ is the gravity effect due to the density contrast of the upper mantle, $g_{s}$ is the gravity effect due to the density contrast of the sediment, and $g_{c}$ is a constant offset, possibly representing deeper density variation. The approach used in this study is similar to that of Cordell and Henderson (1968), in which each gravity value has a depth point in the model directly under it and the model is iterated until the gravity calculated from the whole model fits the data. In this case, we consider a 2D model that continues to infinity in the perpendicular direction; each gravity-anomaly value lies directly above a model vertex in the basement surface and the Moho surface. We iterate the model at each point independently based on the difference between the observed gravity $g_{\mathrm{obs}}$ and the gravity $g_{\text {calc }}$ calculated from the last result from the iterative inversion process. We use the "gpoly" algorithm (Blakely, 1995) for the forward calculation of the gravity effect of the updated model.

The Bouguer slab model is used to inform the iteration, but because the basement and Moho surfaces are linked by equation 1, we cannot consider both these interfaces in the iteration because they would always balance. Instead, we focus on the upper (basement) surface because it will have a bigger local effect at the gravity-observation point than the Moho surface. The iteration is based on the increase or decrease in the sedimentary thickness that would give a gravity anomaly equal to the difference between the observed and previously calculated gravity anomaly. The basement depth is iterated at each stage by

$$
\left(h_{s}\right)_{\text {new }}=\left(h_{s}\right)_{\text {old }}+\alpha \frac{g_{\mathrm{obs}}-g_{\mathrm{calc}}}{2 \pi G \Delta \rho_{s}},
$$

where $\left(h_{s}\right)_{\text {new }}$ and $\left(h_{s}\right)_{\text {old }}$ are the depths to basement after and before the iteration, respectively, $G$ is the gravitational constant, and $\alpha$ is the iteration factor that controls the step size of the iteration process. The depth to Moho is then updated according to equation 1.

Once each point in the model has been iterated, the gravity effect of the new model is calculated. A further iteration is defined based upon the difference between the new $g_{\text {calc }}$ and $g_{\text {obs }}$. The process is repeated until the root-mean-square (rms) difference between $g_{\text {calc }}$

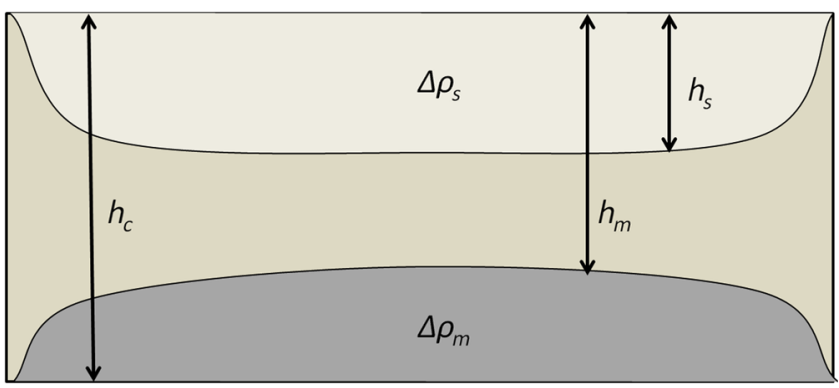

Figure 1. Physical constraints imposed by the Airy isostatic model, showing the relationship between basement depth and Moho depth. The $\Delta \rho_{s}$ value is the (negative) density contrast of the sediments relative to the basement, the $\Delta \rho_{m}$ value is the (positive) density contrast at the Moho (upper mantle relative to lower crust), and the $h_{c}$ value is the Moho depth for basement depth of zero. and $g_{\mathrm{obs}}$ is below a predefined tolerance. The tolerance is defined on a case-by-case basis.

The convergence of the iteration defined by equation 3 is found to depend on the iteration factor $\alpha$. For the model example, $\alpha=1.0$ iterates quickly to fit the data, with slightly higher iteration factors reaching the solution more quickly. However, for the real-data example, an iteration with $\alpha=1.0$ does not converge to a good fit to the data. In general, a lower value of $\alpha$ is more likely to give convergence, albeit after a higher number of iterations.

For a realistic example, there is likely to be some regional component of the gravity field (represented by $g_{c}$ in equation 2), which must be removed before it is possible to invert for the basement and Moho surfaces. This regional component (the simplest case being a uniform offset of the gravity data across the survey area) will prevent the gravity model from converging to fit the gravity data precisely, so we remove it by adjusting the data profile during the iteration process. The regional adjustment can be approximated based upon control data, but consecutive minor adjustments will still be required until the gravity data and the model fit well, because the adjustment will be based on infinite slabs, whereas the models are 2D; interfering basement and Moho anomalies will also complicate the situation. An alternative approach is to add a second iteration to the process in which the whole gravity observation profile is adjusted by $g_{\text {adj }}$ to transform the previous gravity data values $\left(g_{\text {obs }}\right)_{\text {old }}$ to the new values $\left(g_{\text {obs }}\right)_{\text {new }}$ :

$$
\left(g_{\text {obs }}\right)_{\text {new }}=\left(g_{\text {obs }}\right)_{\text {old }}+g_{\text {adj }} \text {, }
$$

where

$$
g_{\text {adj }}=\frac{1}{n} \sum_{i=1}^{n}\left(g_{\text {calc }}-g_{\text {obs }}\right)
$$

and $n$ is the number of gravity observations. This gravity adjustment is applied to the measured gravity data after each iteration of equation 3 to remove the regional component that cannot be removed based on the limited control points. This dual iteration is found to converge rapidly to a stable solution.

\section{MODELED-DATA EXAMPLE}

We created a gravity data set over a simple three-layer rift model (Figure 2a) with basement, and Moho surfaces related by equation 1 . We used a density contrast of $-400 \mathrm{~kg} / \mathrm{m}^{3}$ between sediments and basement and a density contrast of $500 \mathrm{~kg} / \mathrm{m}^{3}$ between the upper mantle and the crust. The gravity data were calculated along a 200$\mathrm{km}$ profile with a sample spacing of $1 \mathrm{~km}$ located above the model nodal points. We added a value of $10 \mathrm{mGal}$ to the calculated anomaly, simulating a constant offset in the gravity anomaly. We then contaminated the shifted gravity anomaly data with random noise with zero mean and a standard deviation of $0.5 \mathrm{mGal}$.

Figure $2 b$ is the resultant Bouguer anomaly profile that shows a negative anomaly from the sedimentary basin superimposed onto a positive anomaly from the crustal thinning; even though the positive anomaly is far from complete in this window, we attempt to invert for both the surfaces. We started with a simple plane-layer model (Figure 2c), which necessarily fits equation 1 . The model is considered to extend horizontally to infinity at the ends of the model, and hence, the gravity anomaly calculated from this starting model is 
constant. We used the model values for $\Delta \rho_{s}, \Delta \rho_{m}$, and $h_{c}$ in the inversion. We also used the depth to basement at a horizontal location of $50 \mathrm{~km}$ as a depth control to remove an initial estimate of the offset from the gravity data $(12.9 \mathrm{mGal})$. The inversion process iterates from the initial model using equation 3 (iteration factor of 1.0) and equation 4 until the rms difference between the theoretical gravity anomaly data and the calculated gravity anomaly of the updated model has been reduced from approximately $13 \mathrm{mGal}$ to below the tolerance of $0.2 \mathrm{mGal}$, after 11 iterations in this case (Figure 2d). Figure 2e shows the value of the adjustment in equation 5 at each iteration. The iterative gravity adjustment started with $3.0 \mathrm{mGal}$ and reduced to $-0.02 \mathrm{mGal}$ after 11 iterations with a final estimate of the offset from the gravity data of $9.7 \mathrm{mGal}$. Figure $2 \mathrm{f}$ shows that the final result for the test model fits very closely with the basement and Moho surfaces, and Figure $2 \mathrm{~g}$ shows the close fit of the calculated and original model gravity anomalies. a)

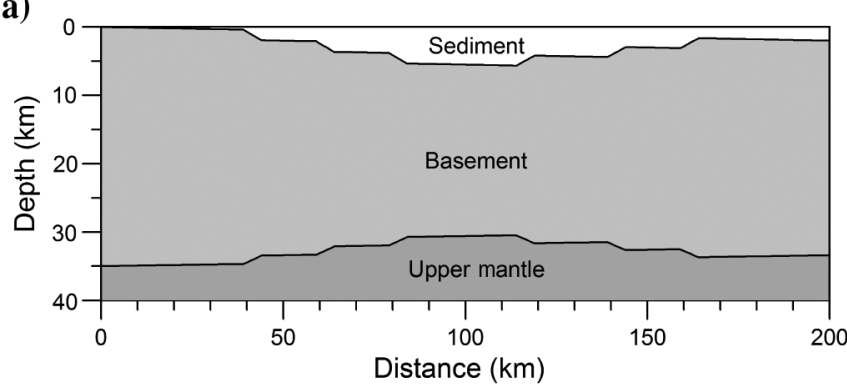

b)

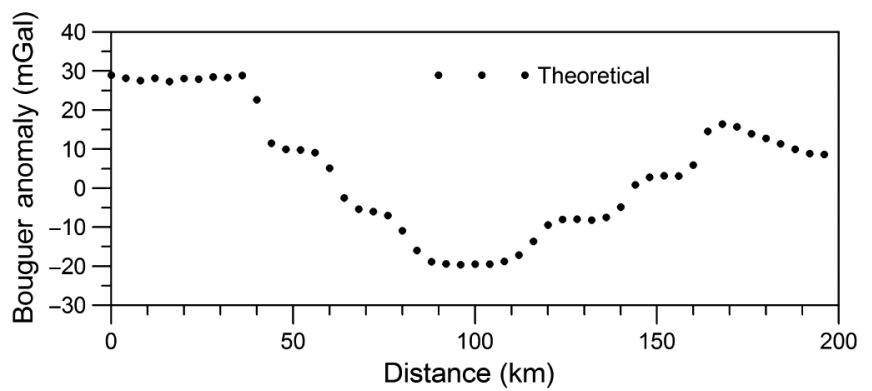

c)

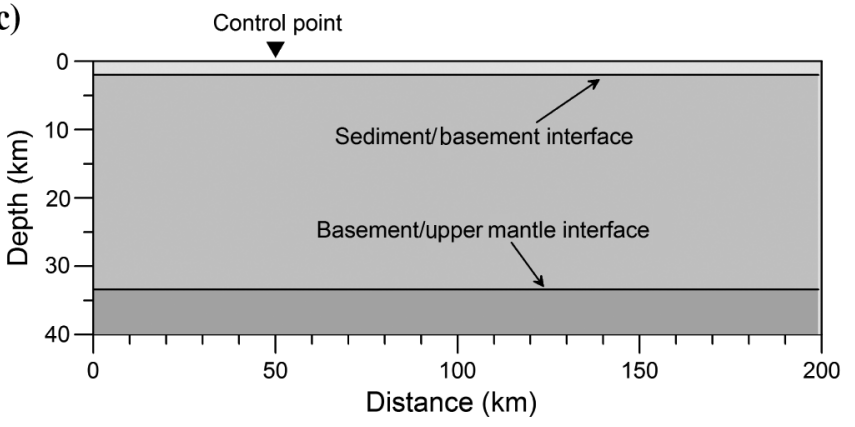

d)

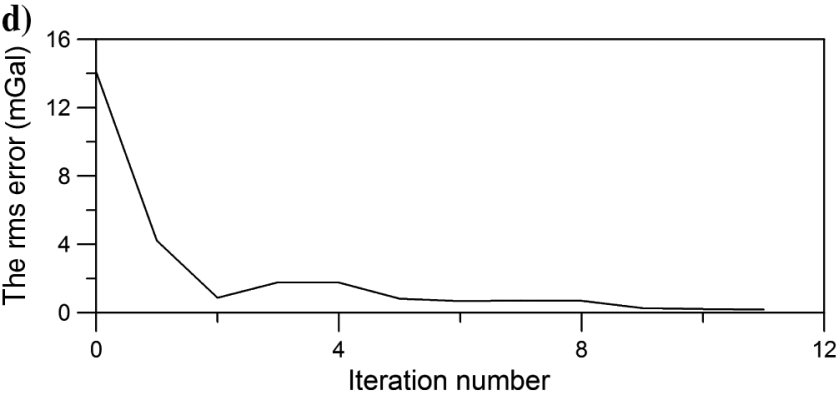

e)

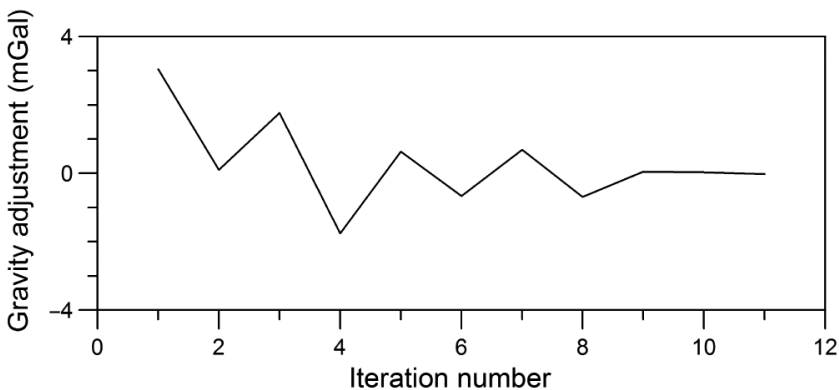

f)

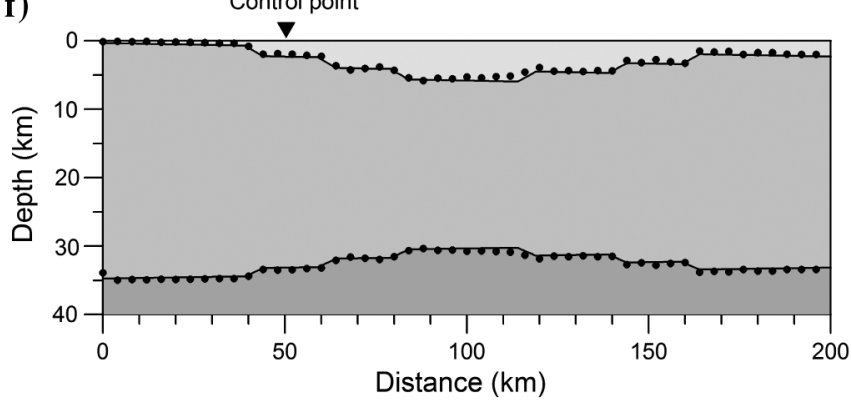

g)

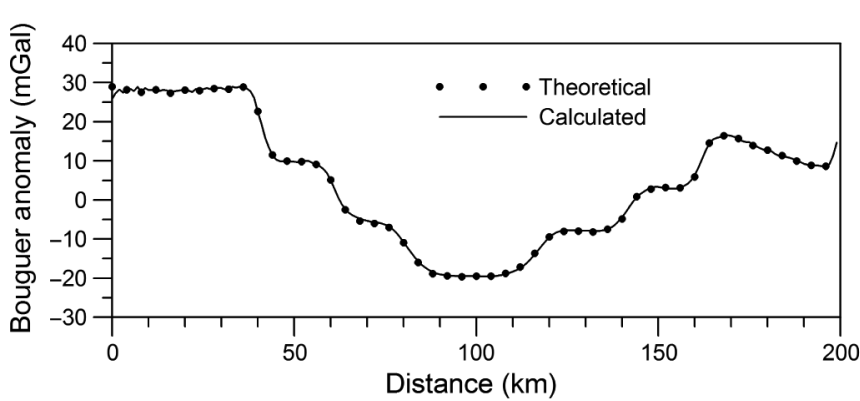

Figure 2. Inversion process for a rift basin model. (a) Three-layer model, (b) gravity anomaly from the model (every fourth point marked with a symbol), (c) initial model for inversion, (d) the rms mismatch between the gravity from the model and the gravity from the result after each iteration, (e) value of gravity adjustment after each iteration, (f) final inverted result of sediment/basement and crust/upper mantle interfaces (circles) compared with the model (lines), and (g) gravity anomaly for the final result (lines) compared with the model (circles). 


\section{FIELD-DATA EXAMPLE}

We demonstrate the practical utility of the approach using gravity data over the Kosti rift Basin in Sudan (Figure 3a). The Kosti Basin is located just to the west of the Blue Nile River and is one of the smallest of several northwest-southeast-trending Cretaceous rift basins thought to have been formed as a result of lateral movement along the Central African Shear Zone (Browne et al., 1985; Jorgensen and Bosworth, 1989; El Tahir et al., 2013). The basin is largely covered by surficial deposits of unconsolidated Cenozoic sands, gravels, shales, and clays with some Cretaceous clastic sediments and Precambrian basement outcropping to the northeast.

A $65-\mathrm{km}$ southwest-northeast gravity profile across the basin was used to test the inversion method. This profile follows part of a longer profile interpreted by Jorgensen and Bosworth (1989). The purpose of using a limited profile length was to test the algorithm in a more challenging and realistic situation, in which data gaps and interfering anomalies often make it impossible to invert the complete anomaly. The Bouguer anomaly across the Kosti Basin (Figure $3 b$ ) shows the classic rift basin anomaly pattern of a central low from the thick sediments superimposed on a broader high from crustal thinning without apparent interference from other gravity anomalies; as such, it should provide a good example for the inversion method.
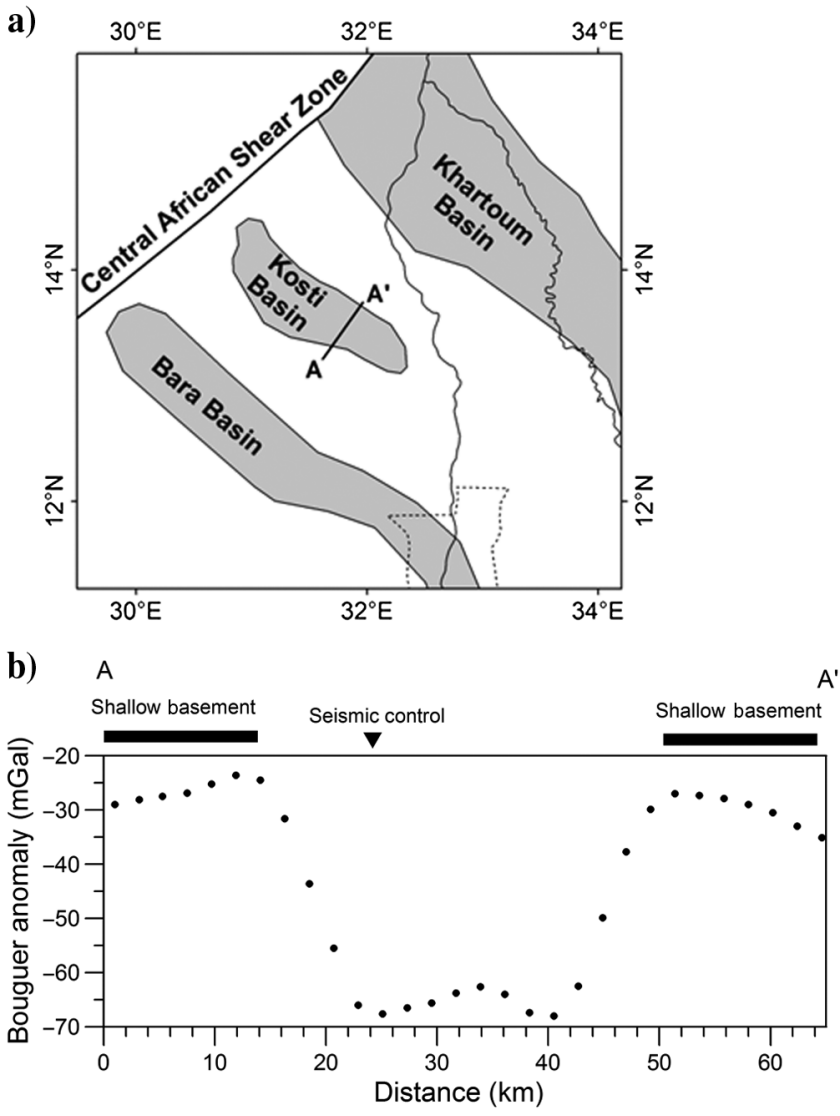

Figure 3. (a) Location of gravity profile $A-A^{\prime}$ across the Kosti rift Basin in Sudan. Basin outlines are modified from El Tahir et al. (2013). (b) Gravity anomaly along profile A-A' (modified from Jorgensen and Bosworth, 1989).
A starting model was created with densities of $2350 \mathrm{~kg} / \mathrm{m}^{3}$ for the sediments, $2700 \mathrm{~kg} / \mathrm{m}^{3}$ for the crustal rocks, and $3300 \mathrm{~kg} / \mathrm{m}^{3}$ for the upper mantle and $h_{c}=30 \mathrm{~km}$ - all as used by Jorgensen and Bosworth (1989). To estimate an initial regional offset from the observed gravity data, we used a depth-control point at the shallowbasement point closest to the basin (horizontal location $13 \mathrm{~km}$ ). This control point provided an initial estimate of the offset of approximately $-23.3 \mathrm{mGal}$, which was then removed from the observed gravity data. To estimate appropriate densities, we used another control point $(3.7 \mathrm{~km}$ depth at $24 \mathrm{~km}$ along profile) based on the seismic interpretation of Jorgensen and Bosworth (1989).

The inversion process was iterated (with iteration factor 0.5 ) reducing the rms error between the observed and calculated gravity to $0.17 \mathrm{mGal}$ after 40 iterations (Figure $4 \mathrm{~b}$ ). The iterative gravity adjustment (Figure 4c) started with $16.2 \mathrm{mGal}$ and reduced to $-0.04 \mathrm{mGal}$ after 40 iterations with a final estimate of the offset from the gravity data of $-38.9 \mathrm{mGal}$. The resulting model (Figure 4a) fits the data well (Figure 4d) but has some large, short-wavelength variations in the depth to the basement not seen in the model of Jorgensen and Bosworth (1989). The depth-to-basement result at the location of the seismic depth-control point is overestimated by $1.9 \mathrm{~km}$ (Figure 4e); this discrepancy is seen to increase beyond iteration five, which causes some concern about the inversion.

The iterative inversion was rerun using a slightly different density scheme: $2350 \mathrm{~kg} / \mathrm{m}^{3}$ for the sediments, $2800 \mathrm{~kg} / \mathrm{m}^{3}$ for the crustal rocks, and $3300 \mathrm{~kg} / \mathrm{m}^{3}$ for the upper mantle. The rms error between the observed and calculated gravity reduced to $0.16 \mathrm{mGal}$ after 17 iterations (Figure 5b). The iterative gravity adjustment (Figure 5c) started with $17.7 \mathrm{mGal}$ and reduced to $0.02 \mathrm{mGal}$ after 17 iterations with a final estimate of the offset from the gravity data of $-39.0 \mathrm{mGal}$. This indicates that estimation of the gravity offset is not affected by using a different density scheme.

The resulting model (Figure 5a) also fits the data well (Figure 5d). The depth-to-basement results with the new density fit the seismic control better (Figure 5e) and have less extreme depth variations. The Moho depth model still has much greater variation than the model of Jorgensen and Bosworth (1989); their Moho model, however, is very likely to be smooth because the regional gravity from which it was modeled contains only very long wavelengths, having been generated from low-order polynomials.

\section{DISCUSSION}

The application of the iterative inversion approach to generate basement and Moho surfaces has generally been successful. A few observations can be made. It appears that the starting model is not particularly important and that the method will iterate to a robust model that fits the data well, even from a very simple starting model with no structure. However, the densities used in the model are important; it appears from the field-data example (Figures 4 and 5) that changing the densities in the model slightly can generate a much more (or less) realistic depth model. On the other hand, it appears that the method could be diagnostic of whether the densities used are correct, such that testing which densities give best convergence could form part of a standard workflow. Different densities can be assessed based on how rapidly the inversion reaches the required rms misfit and whether the control data misfit is large or unstable. Better control data should help to identify correct densities earlier in the process; specific density information could be used, or appropriate densities could be determined from depth-control points 
combined with gravity values. The gravity anomaly offset is also important and significant offsets in the data can limit the convergence to a robust solution. A method has been developed to iteratively solve for the gravity offset, but this is based on the assumption of a simple shift in the gravity data. If the regional gravity field is more complicated, then removing the very longest wavelengths prior to the inversion might be required to generate good results.

Applying the method in 3D is an obvious next step. Extension to $3 \mathrm{D}$ is conceptually straightforward. Some complications are likely to occur in the details of how the regional field is defined or in how the model is extended at the edge. The Moho is normally deep, and gravity anomalies caused by it are generally long wavelength, making it difficult to resolve its shape in detail from gravity data. In this study, we impose a strict adherence to Airy isostacy, but unless we have access to other information, it will be difficult to decide whether the rough Moho surfaces derived from this iterative inver- sion approach are inherently better or worse than smooth Moho surfaces, such as those interpreted by Jorgensen and Bosworth (1989).

\section{CONCLUSION}

From tests on a modeled gravity data set and a field data set of a simple rift basin anomaly, we find that it is possible to invert for basement and Moho surfaces together, provided the two are strictly linked with an equation based on the Airy isostatic model. This is despite the fact that the two gravity effects tend to counteract each other. The method appears to consistently converge to a result that fits the gravity data very well and also replicates test models to great accuracy. This method appears to offer an alternative to approaches that split the data into regional and residual fields using a mathematical approach - either wavelength filtering or polynomial separation. The new method does not make a mathematical assumption but relies on a reasonable physical model of isostacy; a)

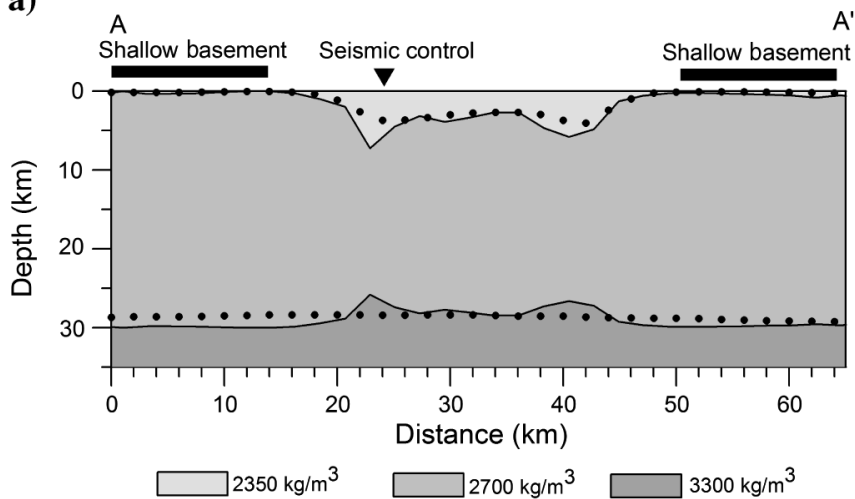

b)

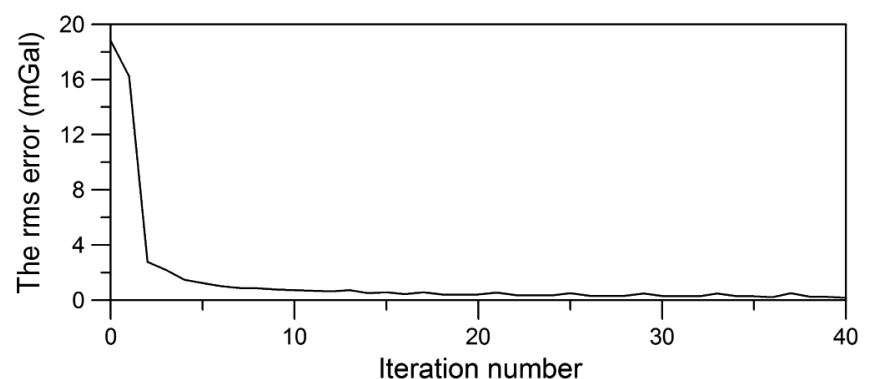

c)

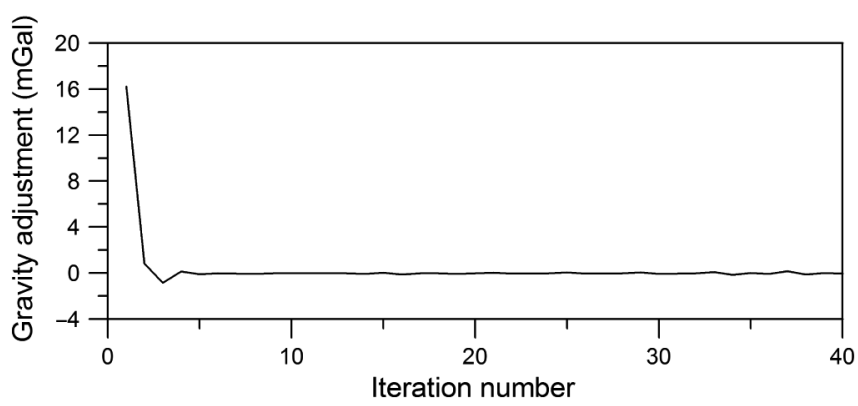

d)

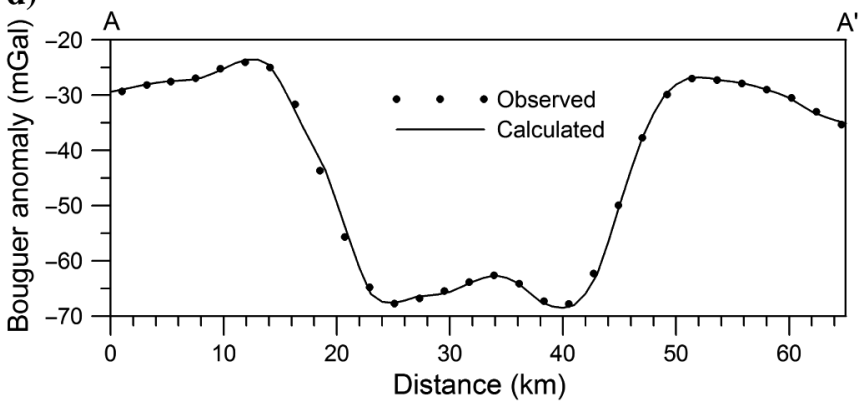

e)

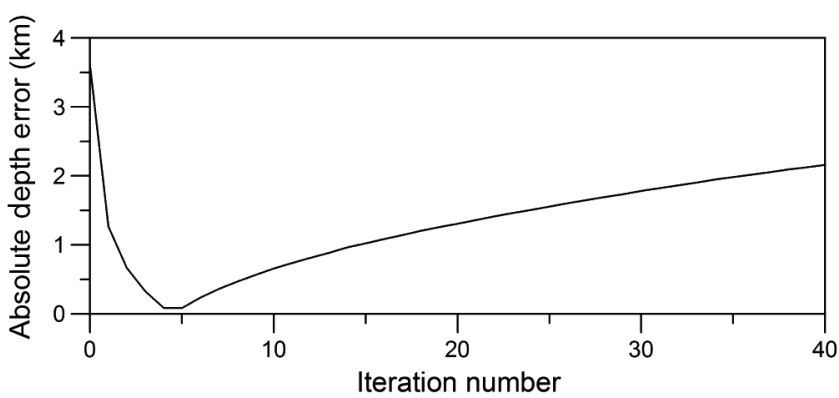

Figure 4. Inversion results for the Kosti Basin. (a) Basement and Moho surfaces. The dotted lines are the interpretation of Jorgensen and Bosworth (1989). (b) The rms mismatch between the gravity from the model and the observed gravity after each iteration, (c) value of gravity adjustment after each iteration, (d) gravity anomaly for the resultant model (lines) compared with the observed gravity data (circles), and (e) absolute depth error at the location of the seismic depth-control point. 
a) $\mathrm{A}$

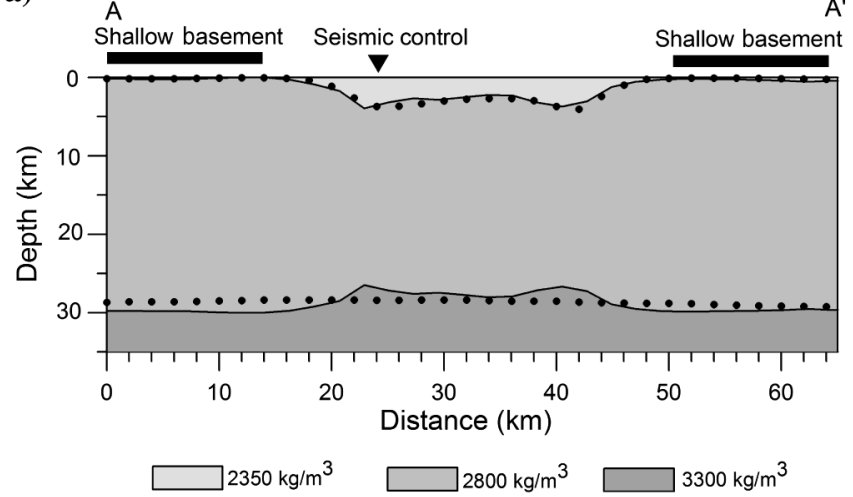

b)

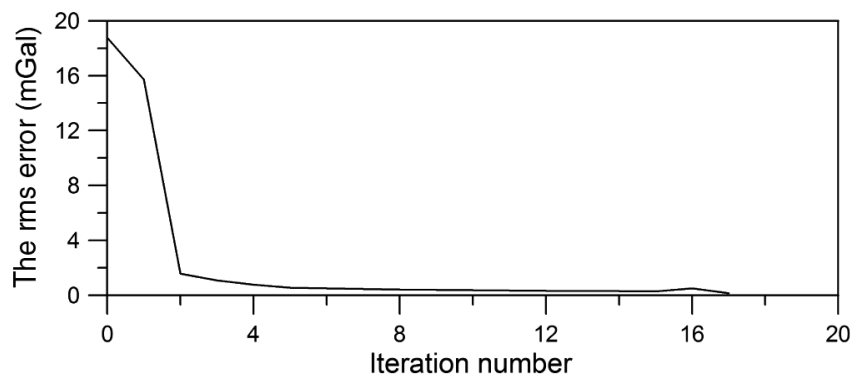

c)

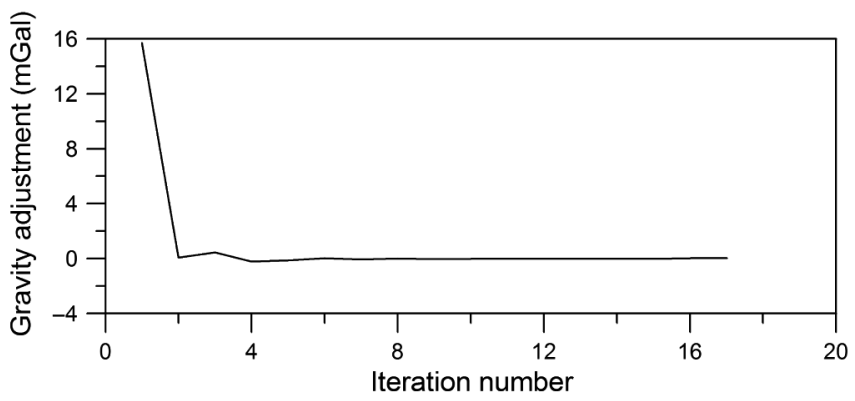

e)

d)

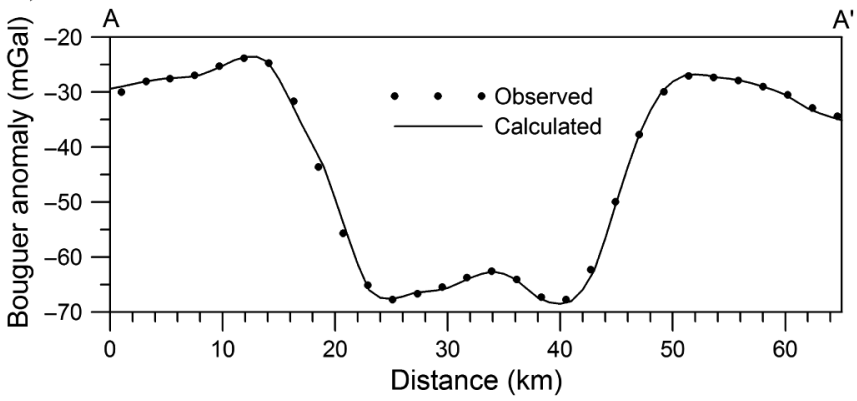

)

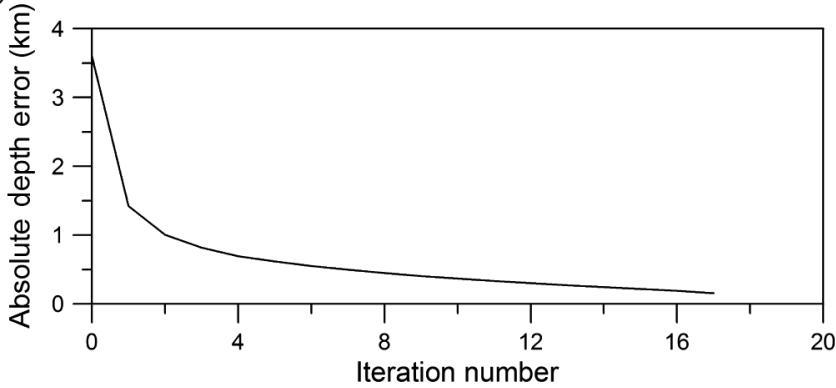

Figure 5. Same as Figure 4 but with a revised crustal density.

as such, it has the promise to produce more realistic models that inherently fit with physical principles. As yet, the method has only been tested in rather simple situations; application to more complex geologic problems will require a greater quantity of control data and/or a more complete understanding of the relationship between the different parts of the model.

\section{ACKNOWLEDGMENTS}

We greatly appreciate the constructive and thoughtful comments of J. Rickett and three anonymous reviewers. We thank R. Blakely, S. Campbell, and S. Mazur for their help in discussion and comments on this work.

\section{REFERENCES}

Blakely, R. J., 1995, Potential theory in gravity and magnetic applications: Cambridge University Press.

Browne, S. E., J. D. Fairhead, and I. I. Mohamed, 1985, Gravity study of the White Nile Rift, Sudan, and its regional tectonic setting: Tectonophysics, 113, 123-137, doi: 10.1016/0040-1951(85)90113-1.
Cordell, L., and R. Henderson, 1968, Iterative three-dimensional solution of gravity anomaly data using a digital computer: Geophysics, 33, 596-601, doi: $10.1190 / 1.1439955$.

El Tahir, N., A. Nyblade, J. Julià, and R. Durrheim, 2013, Crustal structure of the Khartoum Basin, Sudan: Tectonophysics, 593, 151-160, doi: 10 $.1016 /$ j.tecto.2013.02.032.

Fairhead, J. D., and C. M. Green, 1989, Controls on rifting in Africa and the regional tectonic model for the Nigeria and East Niger rift basins: Journal of African Earth Sciences (and the Middle East), 8, 231-249, doi: 10 .1016/S0899-5362(89)80027-2.

Jorgensen, G. J., and W. Bosworth, 1989, Gravity modeling in the Central African Rift System, Sudan: Rift geometries and tectonic significance: Journal of African Earth Sciences (and the Middle East), 8, 283-306, doi: 10.1016/S0899-5362(89)80029-6.

Karner, G. D., and A. B. Watts, 1982, On isostacy at Atlantic-type continental margins: Journal of Geophysical Research, 87, 2923-2948, doi: 10.1029/JB087iB04p02923.

Oldenburg, D. W., 1974, The inversion and interpretation of gravity anomalies: Geophysics, 39, 526-536, doi: 10.1190/1.1440444.

Salem, A., C. Green, S. Campbell, J. Fairhead, L. Cascone, and L. Moorhead, 2013, Moho depth and sediment thickness estimation beneath the Red Sea derived from satellite and terrestrial gravity data: Geophysics, 78, no. 5, G89-G101, doi: 10.1190/geo2012-0150.1.

Watts, A. B., and J. Stewart, 1998, Gravity anomalies and segmentation of the continental margin offshore West Africa: Earth and Planetary Science Letters, 156, 239-252, doi: 10.1016/s0012-821x(98)00018-1. 